\title{
Persistência do herbicida Acetochlor em função de sistemas de preparo e cobertura com palha
}

\author{
Acetochlor herbicide persistence as function of tillage systems \\ and straw mulch presence
}

\author{
Miguel Vicente Weiss Ferri ${ }^{1}$ Ribas Antonio Vidal ${ }^{2}$
}

\section{RESUMO}

Diferentes sistemas de manejo do solo alteram a persistência dos herbicidas e influem na atividade biológica, potencial de injúria às culturas em sucessão e risco de contaminação ambiental. O experimento foi conduzido, no ano agrícola de 2000/2001, na Faculdade de Agronomia da Universidade Federal do Rio Grande do Sul, com o objetivo de avaliar a persistência do herbicida acetochlor em Argissolo Vermelho manejado sob o sistema de semeadura direta $e$ preparo convencional na presença e ausência de palha. A dose utilizada do herbicida foi de $5040 \mathrm{~g} \mathrm{ha}^{-1}$. A persistência foi avaliada através de bioensaio utilizando-se o trigo (Triticum aestivum L.) como planta teste. Foi avaliada a altura da parte aérea das plantas de trigo. A meia vida ( $t$ ) do herbicida no solo foi de 29 e 30 dias na presença e dé 18 e 16 dias na ausência de palha nos solos conduzidos sob semeadura convencional e direta, respectivamente. A palha, na superficie do solo, aumentou a persistência do herbicida acetochlor no solo.

Palavras-chave: bioensaio, semeadura direta, semeadura convencional.

\section{ABSTRACT}

The different soil management systems affects herbicide persistence and change the biological activity, crop selectivity and potencial to environmental risk. An experiment was carried out at the Universidade Federal do Rio Grande do Sul, with the objective of evaluating the persistence of the acetochlor herbicide on tillage and conventional tillage systems with and without straw mulch on soil surface. The soil is classified as Paleudult, and the herbicide dosis sprayed was $5040 \mathrm{~g} \mathrm{ha}^{-1}$. The persistence of acetochlor herbicide was evaluated in a biossay, using wheat (Triticum aestivun L.) as test plant. Assessements included plant height. The acetochlor herbicide half-life was 29 and 30 day on straw mulch presence, and 18 e 16 days on straw mulch absence at the conventional tillage and no-tillage systems, respectively. Straw mulch increased acetochlor herbicide persistence in the soil.

Key works: bioassay, no tillage, conventional tillage.

\section{INTRODUÇÃO}

A persistência dos herbicidas no solo exerce influência marcante sobre o controle das plantas daninhas, a injúria para as culturas em sucessão e o risco de contaminação ambiental. A persistência varia com a adsorção, lixiviação e degradação e/ou transformação biológica, pois esses fatores regulam a concentração, o fluxo e o tempo de permanência das moléculas destes compostos na solução do solo (LOUX et al. 1989). Além disso, a importância e a intensidade da ação destes fatores sobre a persistência dependem das condições edafo-climáticas específicas aos locais de estudo (WALKER et al., 1992).

A degradação microbiológica dos herbicidas é o principal mecanismo de decomposição e, desta forma, de redução da persistência dos herbicidas no solo. Normalmente, incrementos na dissipação são esperados com o aumento do teor de

'Engenheiro Agrônomo, Doutor, CP 138, 85550-000, Coronel Vivida, Pr. E-mail: mvwferri@bol.com.br. Autor para correspondência.

${ }^{2}$ Engenheiro Agrônomo PhD., Professor, Departamento de Plantas de Lavoura, Faculdade de Agronomia, UfRGS, Av. Bento Gonçalves 7712, 91501-970, Porto Alegre, RS. 
matéria orgânica, aeração, umidade e temperatura do solo. Isso ocorre porque esses fatores regulam a atividade, a biomassa e a diversidade microbiana no solo e, em função disso, as possíveis transformações biológicas dos herbicidas no solo (WALKER et al., 1992).

A lixiviação reduz a persistência dos herbicidas por promover o transporte desses compostos para região do solo pouco explorada pelas raízes das plantas daninhas e culturas. Como conseqüência, reduz-se a eficácia de controle das plantas daninhas e o potencial de injúria para as culturas em sucessão. No entanto, ela pode incrementar o risco de contaminação de águas subterrâneas. A intensidade com que a lixiviação atua na redução da persistência dos herbicidas depende das taxas de adsorção e decomposição e/ou transformação biológica destes compostos no solo (GUO et al., 1993; WEED et al. 1995) e do grau de cobertura do solo com palha (JONES et al., 1990; REDDY et al., 1997).

Os sistemas de manejo do solo influem na persistência dos herbicidas no solo por alterar o teor de matéria orgânica, umidade e temperatura desse, o que modifica as taxas de adsorção e degradação biológica e, por conseqüência, a persistência dos herbicidas. Além disso, a manutenção da estabilidade da estrutura, com possível ocorrência de fluxo preferencial, pode favorecer a lixiviação dos herbicidas nos solos sob semeadura direta e incrementar sua dissipação no solo (WALKER et al., 1992; SHIPITALO et al., 2000). Variações na dissipação de herbicidas cloroacetamidas ocorrem entre solos conduzidos sob semeadura direta e convencional. O herbicida alachlor pode decompor-se rapidamente no solo, com meiavida $\left(\mathrm{t}_{1 / 2}\right)$ entre 2 e 60 dias, dependendo das características edafo-climáticas (BEESTMAN \& DEMING, 1974; POTHULURI et al., 1990; WALKER et al., 1992). Segundo JONES et al. (1990) a dissipação do herbicida alachlor foi mais rápida na semeadura direta, sendo isto atribuído às variações no teor de matéria orgânica, umidade, atividade e biomassa microbiana do solo. Ao estudar a dissipação dos herbicidas acetochlor, alachlor e metolachlor, em diferentes solos submetidos à semeadura convencional e em dois anos seguidos, MUELLER et al. (1999) verificaram que a meia-vida destes herbicidas foram de 6, 7 e 14 dias, respectivamente.

A cobertura com palha também pode afetar a persistência dos herbicidas aplicados ao solo. A adsorção dos herbicidas, aos resíduos das plantas, pode reduzir sua liberação para o solo e, em função disso, pode afetar a atividade e a persistência destes compostos no solo (REDDY et al., 1997). Além disso, a retenção dos herbicidas, pelos resíduos das plantas pode minimizar as perdas por ersão hídrica e lixiviação (REDDY et al., 1995). Ao estudar o efeito da palha sobre a atividade dos herbicidas acetochlor, alachlor e metolachlor, BANKS \& ROBINSON (1986) obtiveram que a atividade e a persistência destes herbicidas variaram com o incremento do conteúdo de palha sobre a superfície do solo.

Este trabalho tem por objetivo avaliar a persistência do herbicida acetochlor em solo submetido à semeadura direta e ao preparo convencional na presença e ausência de cobertura com palha.

\section{MATERIAL E MÉTODOS}

O experimento foi conduzido a campo, no ano agrícola de 2000/2001, na Estação Experimental Agronômica da Universidade Federal do Rio Grande do Sul (EEA/UFRGS), em Eldorado do Sul, região fisiográfica da Depressão Central do Estado. Os bioensaios foram feitos em laboratório, no Departamento de Plantas de Lavoura da Faculdade de Agronomia UFRGS. O solo utilizado é classificado pelo Sistema Brasileiro de Classificação de Solos (EMBRAPA, 1999) como Argissolo Vermelho Distrófico típico, contendo $28 \%$ de argila e manejado sob semeadura direta ( 7 anos consecutivos) e preparo convencional (15 anos consecutivos).

$\mathrm{O}$ herbicida acetochlor (2-cloro-N(etoximetil)-N-(2-etil-6-metil-fenil), pertence ao grupo químico das acetamida e atua como inibidor da parte aérea das plantas e foi aplicado em 31 de outubro de 2000, na dose de 5040g ha-1. A aplicação foi realizada com pulverizador costal pressurizado à pressão de $200 \mathrm{kPa}$, bicos de jato plano (tipo "leque") 8002 , distanciados em $0,50 \mathrm{~m}$ na barra de $1,5 \mathrm{~m}$ e volume de calda equivalente a $220 \mathrm{~L} \mathrm{ha}^{-1}$. As condições edafo-climáticas, durante a aplicação do herbicida, foram: solo úmido; umidade relativa do ar de $70 \%$, velocidade do vento inferior a $10 \mathrm{~km} \mathrm{~h}^{-1} \mathrm{e}$ insolação plena. A temperatura média, a campo, durante a condução do experimento, foi de $24^{\circ} \mathrm{C}$.

$\mathrm{O}$ delineamento experimental utilizado foi o de blocos casualizados, com três repetições, sendo os tratamentos distribuídos em parcelas sub-subdivididas. Nas parcelas principais, encontram-se o preparo de solo: semeadura direta e preparo convencional: Nas sub-parcelas, a cobertura do solo com palha $\left(4,5 \mathrm{t} \mathrm{ha}^{-1}\right)$ e sem palha, e, nas subsub-parcelas, as épocas de avaliação: 1, 7 14, 35 e 70 dias após tratamento com o herbicida acetochlor (DAA). 
A cobertura do solo, nos solos sob semeadura direta e preparo convencional, foi obtida depositando-se palha de aveia-preta (Avena strigosa Schreb.) sobre o mesmo. Na semeadura direta, a vegetação existente sobre a superfície do solo foi controlada com paraquat, a $800 \mathrm{~g} \mathrm{ha}^{-1}, 5$ dias antes e no dia da implantação do experimento. Durante a condução do experimento, foram realizadas irrigações de $18 \mathrm{~mm}$ de água as 3 horas e aos 14, 28, 35 e 70 DAA. A precipitação pluvial média mensal durante a condução do experimento, foi de $26 \mathrm{~mm}$.

A persistência do herbicida acetochlor no solo foi determinada através de bioensaio, utilizandose o trigo (Triticum aestivum L.) como planta teste. A profundidade de solo estudada foi de $10 \mathrm{~cm}$. O bioensaio foi realizado em colunas de solo coletadas pela introdução de tubos de PVC de 50mm de diâmetro e $20 \mathrm{~cm}$ de profundidade no solo aos 1, 714,35 e 70 DAA. Em todas as épocas e em ambos os sistemas de preparo, com ou sem palha, foram coletados também, colunas de solo sem o acetochlor, utilizado como testemunha. Após cada coleta, as colunas (solo e tubo de PVC) foram armazenadas a $5^{\circ} \mathrm{C}$ para posterior avaliação da persistência. Para isto, as colunas foram cortadas longitudinalmente na região do terçosuperior, permitindo a semeadura de sementes de trigo pré-germinadas no solo presente no interior da coluna. Antes da semeadura das sementes de trigo, o solo presente na coluna foi desestruturado com uso de espátula metálica. O desenvolvimento das plantas ocorreu em laboratório, em câmara de crescimento, à temperatura constante de $22^{\circ} \mathrm{C}$ e fotoperíodo de 12 horas. A resposta das plantas de trigo à presença do acetochlor foi avaliada aos 11 dias da emergência, convertendo-se os valores em porcentagem de redução da altura de plantas em relação à testemunha sem herbicida.

A presença do herbicida acetochlor, para cálculo da meia-vida no solo, foi determinada comparando-se o crescimento das plantas de trigo no solo coletado a campo tratados com o herbicida, com curva de doseresposta obtidas pelo crescimento do trigo em solo contendo acetochlor nas doses de 0,$0 ; 52,0 ; 105,0 ; 210,0 ; 420,0 ; 840,0 ; 1680,0$ e $3360,0 \mathrm{~g} \mathrm{ha}^{-1}$. Após a aplicação do acetochlor, o solo foi agitado manualmente com objetivo de homogeneizar a distribuição do herbicida no mesmo. Em seguida, o solo tratado com acetochlor e não tratado com o herbicida foi transferido para potes com capacidade de $200 \mathrm{~g}$ de solo e semeadas cinco sementes de trigo pré-germinadas. O desenvolvimento das plantas de trigo ocorreu em câmara de crescimento nas mesmas condições ambientais do bioensaio.

A persistência do acetochlor foi calculada através da cinética de dissipação de herbicidas no solo (PAUL \& CLARK, 1996) utilizando-se a equação:

$$
\operatorname{Ln}([\mathrm{Cf}] /[\mathrm{Ci}]=-\mathrm{k}
$$

onde [Ci] e [Cf] são as concentrações do herbicida acetochlor indicadas pelo bioensaio no tempo inicial e final, respectivamente, $\mathrm{k}$ é a constante de dissipação e t é o tempo. A meia-vida $\left(\mathrm{t}_{1 / 2}\right)$ no solo foi calculada pela equação $t_{1 / 2}=0,693 / \mathrm{k}$

$\mathrm{Na}$ análise estatística no bioensaio, foram considerados os valores correspondentes à porcentagem de redução de altura das plantas de trigo em relação à testemunha sem herbicida. O dados sofreram transformação em arco seno $\sqrt{\mathrm{x} / 100}$ ao serem submetidos à análise de variância. A variação da presença do acetochlor no tempo, em função do preparo e cobertura do solo com palha, foi avaliado pelo intervalo de confiança da média pelo teste $\mathrm{t}$ em nível de $5 \%$ de significância. Foi avaliado, também, o grau de correlação entre a meia vida $\left(t_{1 / 2}\right)$ do herbicida acetochlor, preparo e cobertura do solo, verificando-se o nível de significância do coeficiente de correlação (r).

\section{RESULTADOS E DISCUSSÃO}

A redução da altura de plantas variou entre os sistemas de preparo do solo em função da cobertura com palha e épocas de avaliação (Figuras 1 e 2). A palha evitou que o herbicida acetochlor atingisse o

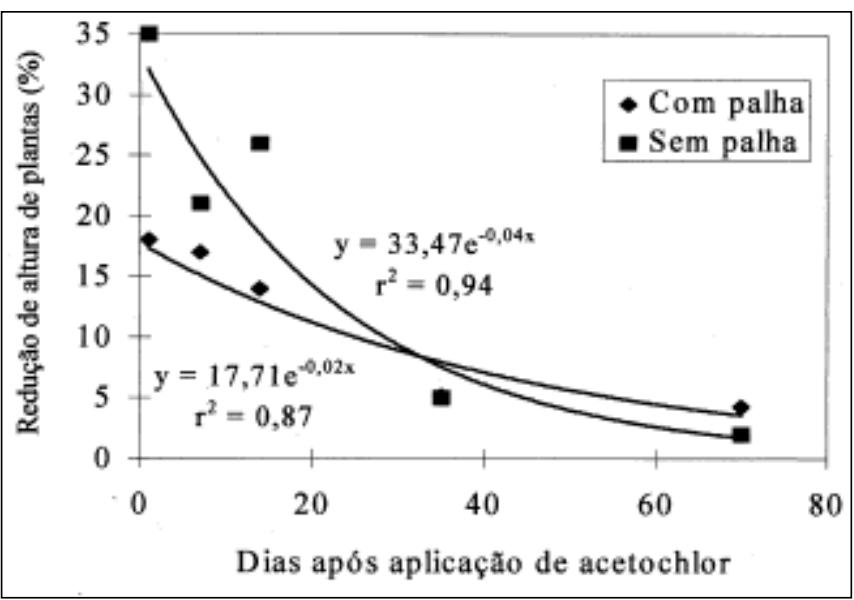

Figura 1 - Redução de altura de plantas de trigo (\%) no tempo, devido à aplicação do herbicida acetochlor em Argissolo Vermelho sob semeadura direta, na ausência ou presença de palha. UFRGS, Porto Alegre, RS, 2000/2001. 


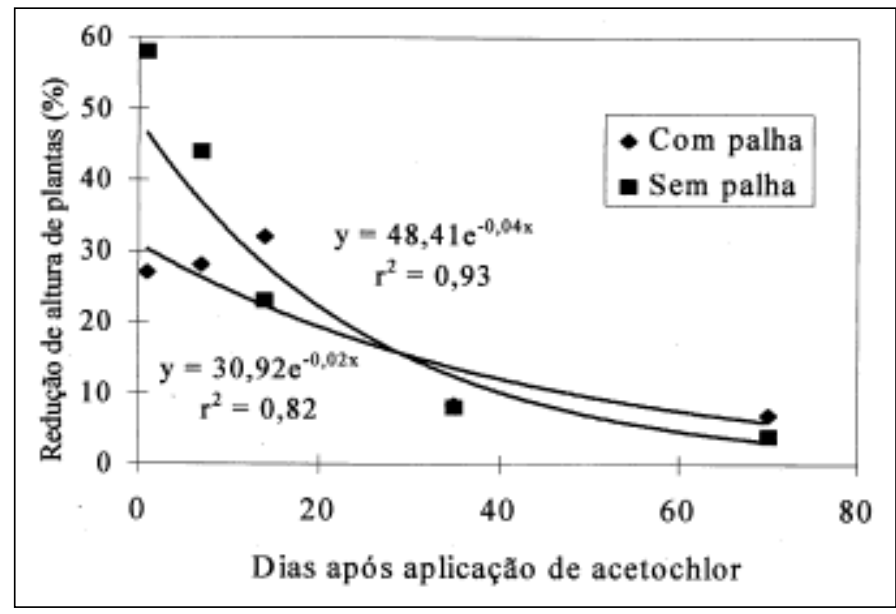

Figura 2 - Redução de altura de plantas de trigo (\%) no tempo, devido à aplicação do herbicida acetochlor em Argissolo Vermelho com preparo convencional, na ausência ou presença de palha. UFRGS, Porto Alegre, RS, $2000 / 2001$.

solo e propiciou menor redução na altura de plantas de trigo, conforme observado nas avaliações iniciais (1 e 7 DAA), em ambos os sistemas de manejo do solo. Supõe-se que a palha possa ter adsorvido o acetochlor e reduzido sua biodisponibilidade no solo e, em função disso, reduziu a absorção pelas raízes da planta indicadora na presença deste herbicida no solo. A palha, na superfície do solo, reduziu a atividade dos herbicidas acetochlor, metolachlor e alachlor segundo BANKS \& ROBINSON, (1986), sendo que menos de $50 \mathrm{e}$ $10 \%$ dos herbicidas aplicados atingiu o solo na presença da palha nas quantidades de 1120 e $4480 \mathrm{~kg} \mathrm{ha}^{-1}$, respectivamente. A interceptação e a retenção de herbicida pela palha, além de afetar a liberação do composto para o solo e a conseqüente absorção pelas raízes das plantas daninhas, pode prolongar a persistência no solo (REDDY et al., 1995; REDDY et al., 1997). A intensidade da ação depende do grau de interação dos herbicidas com os resíduos vegetais e da época e intensidade da precipitação pluvial ou irrigação após aplicação destes compostos (BANKS \& ROBINSON, 1986; REDDY etal., 1995; REDDY etal., 1997).

A curva de calibração do herbicida acetochlor não indicou diferenças de desempenho em solo sob semeadura direta e preparo convencional. A curva de calibração é composta de três segmentos lineares, nos quais o efeito mais pronunciado do herbicida foi constatado em doses compreendidas entre 0 e $210 \mathrm{~g} \mathrm{ha}^{-1}$ (Figura 3). Utilizando-se a curva de calibração e a porcentagem de redução de altura de plantas (Figuras 1 e 2), determinou-se a biodisponibilidade do herbicida acetochlor no tempo, na presença ou ausência de palha sobre a superfície do solo (Tabela 1).

Observou-se a 1 DAA no solo submetido à semeadura direta a 1 e 7 DAA no solo com preparo convencional menor disponibilidade de acetochlor no solo na presença da palha, indicando que ela adsorveu o herbicida, reduzindo sua biodisponibilidade no solo (Tabela 1). A presença da palha reduziu em torno de $52 \%$ a biodisponibilidade do herbicida acetochlor no solo, em ambas as formas de preparo, conforme observado na avaliação realizada 1 DAA. Este resultado evidencia a importância da palha na superfície do solo como fator de redução da atividade de herbicidas residuais, conforme também observaram BANKS \& ROBINSON (1986), REDDY et al. (1997) e RODRIGUES et al. (2000).

A partir de 35 DAA, não foram observadas variações de altura de plantas na presença ou ausência de palha, em ambos sistemas de manejo do solo. A irrigação e a precipitação pluvial, ocorridas no período de avaliação, podem ter promovido a desorção de herbicida acetochlor da palha e promovido sua distribuição no solo. A ocorrência de precipitação pluvial e/ou irrigação promove a desorção dos herbicidas da

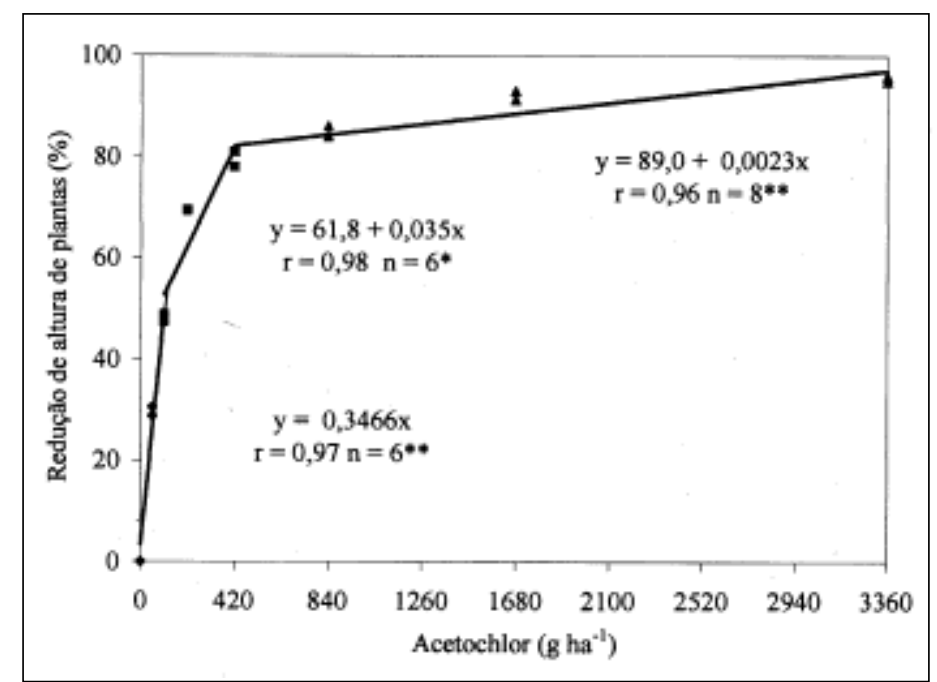

Figura 3 - Redução da altura da plantas de trigo (\%) em função de doses do herbicida acetochlor. $\left(* \mathrm{e}^{* *}\right.$ significativo a $1 \%$ e $5 \%$ de probabilidade respectivamente). EEA/UFRGS, Eldorado do Sul, RS, 2000/01.

Ciência Rural, v. 33, n. 3, mai-jun, 2003. 
Tabela 1 - Biodisponibilidade do herbicida acetochlor em Argissolo Vermelho, em função da época de avaliação, preparo e cobertura do solo. UFRGS, Porto Alegre, RS, 2000/2001.

\begin{tabular}{|c|c|c|c|c|}
\hline \multirow{2}{*}{$\begin{array}{l}\text { Épocas de } \\
\text { avaliação }\end{array}$} & \multicolumn{2}{|c|}{ Semeadura direta } & \multicolumn{2}{|c|}{ Preparo convencional } \\
\hline & Com palha & Sem palha & Com palha & Sem palha \\
\hline & \multicolumn{4}{|c|}{ acetochlor $\left(\mathrm{g} \mathrm{ha}^{-1}\right)$} \\
\hline $1 \mathrm{DAA}^{1}$ & $52 \pm 11^{2}$ & $101 \pm 33$ & $77 \pm 10$ & $166 \pm 45$ \\
\hline 7 DAA & $50 \pm 13$ & $59 \pm 9$ & $81 \pm 14$ & $128 \pm 31$ \\
\hline $14 \mathrm{DAA}$ & $40 \pm 12$ & $77 \pm 7$ & $91 \pm 27$ & $68 \pm 11$ \\
\hline 35 DAA & $15 \pm 4$ & $14 \pm 7$ & $24 \pm 11$ & $23 \pm 10$ \\
\hline 70 DAA & $12 \pm 8$ & $6 \pm 4$ & $20 \pm 10$ & $11 \pm 4$ \\
\hline
\end{tabular}

${ }^{1} \mathrm{DAA}=$ dias após aplicação do acetochlor.

${ }^{2}$ Intervalo de confiança para $5 \%$ de probabilidade de erro pelo teste $\mathrm{t}$.

palha e pode afetar sua atividade biológica, lixiviação e transporte por erosão hídrica segundo BANKS \& ROBINSON(1986), KENIMER etal. (1987) e GREEN et al. (1995), sendo esta a possível explicação para o observado neste trabalho.

Analisando-se a cinética de dissipação do herbicida acetochlor no solo, observou-se que a persistência de acetochlor não variou entre as formas de preparo do solo, tanto na ausência quanto na presença de palha. A meia vida $\left(t_{1 / 2}\right)$ foi de 30 e 29 dias na presença da palha e 16 e 18 dias na sua ausência (Tabela 2), para o preparo convencional e semeadura direta, respectivamente. Estes resultados demonstram que a palha sobre a superfície do solo contribuiu para elevar a persistência do herbicida no solo, em ambos os sistemas de preparo do solo. Entretanto, supõe-se que as irrigações, aliadas às precipitações pluviais, ocorridas no período de avaliação, possam ter uniformizado a distribuição do herbicida acetochlor no solo ou favorecido a sua lixiviação, contribuindo para obtenção de persistência semelhante entre as duas formas de preparo de solos, tanto na presença quanto ausência da palha.

Vários são os benefícios gerados pela palha sobre a superfície do solo. A presença de resíduos de plantas reduz as perdas de agroquímicos, água e solo por erosão hídrica, conserva a umidade do solo, melhora as propriedades físicas, incrementa o teor de carbono orgânico, favorece a diversidade e atividade microbiana do solo (BLEVINS \& FRYE, 1993; REDDY etal., 1995)e auxilia na supressão de plantas daninhas (BURGOS \& TALBERT, 1996). No entanto, a palha pode atuar negativamente, reduzindo a atividade de herbicidas aplicados ao solo (BANKS \& ROBINSON, 1986). A intensidade do efeito varia com a quantidade e o grau de decomposição da palha. $\mathrm{O}$ aumento na quantidade e a presença de resíduos bem decompostos pode aumentar a adsorção e prolongar o tempo de residência de herbicidas à superfície do solo, reduzindo não só a eficácia do controle das plantas daninhas (ADDISCOTT \& DEXTER, 1994; REDDY et al., 1995), bem como aumentando a persistência dos herbicidas aplicados ao solo (REDDY et al., 1997).

A atividade e a persistência de herbicidas varia com a ação de processos de retenção, transferência e transformação dos destes compostos no solo, como adsorção, lixiviaçãoe decomposição microbiológica. A intensidade da ação destes processos depende, primariamente, do contato do herbicida com o solo. Por adsorver as moléculas e protegê-las da ação desses processos, supõe-se que a palha, na superfície do solo, contribuiu para elevar a persistência do herbicida acetochlor no solo.

\section{CONCLUSÃO}

Com base nos resultados observados neste trabalho, conclui-se que a presença da palha na superfície do solo aumenta a persistência do herbicida acetochlor no solo.
Tabela 2 - Coeficientes de correlação (r), constantes de dissipação (k) e meia-vida $\left(\mathrm{t}_{1 / 2}\right)$ do acetochlor em Argissolo Vermelho sob semeadura direta e preparo convencional, na presença ou ausência de palha. UFRGS, Porto Alegre, RS, 2000/2001.

\begin{tabular}{lcccc}
\hline Preparo do solo & & $\begin{array}{c}\text { Coeficientes de } \\
\text { correlação (r) }\end{array}$ & $\mathrm{k}$ & $\mathrm{t}_{1 / 2}$ \\
& & $\left.\mathrm{dia}^{-1}\right)$ & $(\mathrm{dias})$ \\
\hline Semeadura direta & com palha & $0,93^{*}$ & $2,29 \times 10^{-2}$ & 30 \\
& sem palha & $0,96^{* *}$ & $4,24 \times 10^{-2}$ & 16 \\
Preparo convencional & com palha & $0,90^{*}$ & $2,35 \times 10^{-2}$ & 29 \\
& sem palha & $0,96^{* *}$ & $3,94 \times 10^{-2}$ & 18 \\
\hline
\end{tabular}

* Significativo a 5\% de probabilidade de erro.

** Significativo a $1 \%$ de probabilidade de erro.

\section{REFERÊNCIAS BIBLIOGRÁFICAS}

ADDISCOTT, T.M.; DEXTER, A.R. Tillage and crop residue management effects on losses of chemicals from soils. Soil \& Tillage Research, Amsterdam, v.30, n.2-4, p.125-168, 1994.

BANKS, A.P.; ROBINSON, E.L. Soil reception and activity of acetochlor, alachlor, and metolachlor as affeted by wheat (Triticum aestivum) straw and irrigation. Weed Science, Champaign, v.34, n.3, p.607-611, 1986.

BEESTMAN, G.B.; DEMING, J.M. Dissipation of acetanilide herbicides from soils. Agronomy Journal. Madison, v.66, n.1, p.308-311, 1974. 
BLEVINS, R.L.; FRYE, W.W. Conservation tillage: An ecological approach to soil management. Advance in Agronomy. v.51, p.33-78, 1993.

BURGOS, N.R.; TALBERT, R.E. Weed control and sweet corn (Zea mays var. rugosa) response in a no-till system with cover crops. Weed Science, Champaign, v.44, n.2, p.355-361, 1996

EMPRESA BRASILEIRA DE PESQUISA AGROPECUÁRIA EMBRAPA. Serviço Nacional de Pesquisa de Solos. Sistema Brasileiro de Classificação de Solo. Rio de Janeiro, 1999. 412p

GREEN, J.D.; HORTON, R.; BAKER, J.L. Crop residue effects on the leaching of surface-applied chemicals. Journal of Environmental Quality, Madison, v.24, n.2, p.343-351, 1995.

GUO, L. et al. Sorption and movement of alachlor in soil modified by carbon-rich wastes. Journal of Environmental Quality, Madison, v.22, n.1, p.186-194, 1993.

JONES, R.E.; BANKS, P.A.; RADCLIFFE, D.E. Alachlor and metribuzin movement and dissipation in a soil profile as influenced by soil surface condition. Weed Science, Lawrence, v.38, n.2, p.589-597, 1990.

KENIMER, A.L. et al. Effects of residue cover on herbicide losses from conventional and no-tillage systems. Transactions of the ASAE, Saint Joseph, v.30, p.953-959, 1987.

LOUX, M.M.; LIEBL, R.A.; SLIFE, F.W. Availability and persistence of imazaquin, imazethapyr, and clomazone in soil. Weed Science, Champaign, v.37, n.1, p.259-267, 1989.

MUELLER, T.C.; SHAW, D.R.; WITT, W.W. Relative dissipation of acetochlor, alachlor, metolachlor and, SAN 582 from three surface soil. Weed Technology, Champaign, v.13, n.1, p.341-346, 1999 .

PAUL, E.A.; CLARK, F.E. Soil microbiology and biochemistry. 2. ed. San Diego : Academic, 1996. 340p.

POTHULURI, J.V. et al. Aerobic and anaerobic degradation in samples from a surface-to-groundwater profile. Journal of Environmental Quality, Madison, v.19, n.2, p.525-530, 1990.

REDDY, K.N.; ZABLOTOWICZ, R.M.; LOCKE, M.A. Chlorymuron adsorption, desorption and degradation in soils from conventional tillage and no-tillage systems. Journal of Environmental Quality, Madison, v.24, p.760-767, 1995.

REDDY, K.N.; LOCKE, M.A.; GASTON, L.A. Tillage and cover crop effects on cyanazine adsorption and desorption kinetics. Soil Science, Madison, v.150, n.7, p.501-509, 1997.

RODRIGUES, B.N.; LIMA, J. DE; YADA, I.F.U. Retenção pela palhada, de herbicidas aplicados em pré-emergência na cultura do milho, em plantio direto. Revista Brasileira de Herbicidas, Brasília, v.1, n.2, p.123-128, 2000.

SHIPITALO, M.J.; DICK, W.A.; EDWARDS, W.M. Conservation tillage and macropore factors that affect water movement and the fate of chemicals. Soil \&Tillage Research, Amsterdam, v.53, n.3-4, p.167-183, 2000.

WALKER, A.; MOON, Y.; WELCH, S.J. Influence of temperature, soil moisture, and soil characteristics on the persistence of alachlor. Pesticide Science, London, v.35, n.2, p.109-116, 1992.

WEED, D.A.J.et al. Dissipation and distribution of herbicides in the soil profile. Journal of Environmental Quality, Madison, v.24, n.1, p.68-79, 1995. 